\title{
Anti-Invasive Gene Expression Profile of Curcumin in Lung Adenocarcinoma Based on a High Throughput Microarray Analysis
}

\author{
Huei-Wen Chen, Sung-Liang Yu, Jeremy J. W. Chen, Han-Ni Li, Yi-Chen Lin, Pei-Li Yao, \\ Han-Yi Chou, Chiang-Ting Chien, Wen-Jone Chen, Yuan-Teh Lee, and Pan-Chyr Yang \\ Departments of Medical Research (H.-W.C., J.J.W.C., C.T.C.), Surgery (S.-L.Y.), and Internal Medicine (Y.-C.L., P.-L.Y., W.- \\ J.C., Y.-T.L., P.-C.Y.), National Taiwan University Hospital and Institute of Molecular Medicine (H.-Y.C.), National Taiwan \\ University College of Medicine, Taipei, Taiwan; Taipei Medical University, Taipei, Taiwan (H.-W.C., H.-N.L.); Department of Life \\ Science (H.-W.C.), Institute of Biomedical Sciences, and Molecular Biology (J.J.W.C.), College of Life Science, National \\ Chung-Hsing University, Taichung, Taiwan, Republic of China
}

Received June 12, 2003; accepted October 10, 2003

This article is available online at http://molpharm.aspetjournals.org

\begin{abstract}
Curcumin has been reported to exhibit anti-invasive and/or antimetastatic activities, but the mechanism remains unclear. In this study, microarray analysis of gene expression profiles were used to characterize the anti-invasive mechanisms of curcumin in highly invasive lung adenocarcinoma cells (CL1-5). Results showed that curcumin significantly reduces the invasive capacity of CL1-5 cells in a concentration range far below its levels of cytotoxicity $(20 \mu \mathrm{M})$ and that this anti-invasive effect was concentration dependent $\left(10.17 \pm 0.76 \times 10^{3}\right.$ cells at $0 \mu \mathrm{M} ; 5.67 \pm$ $1.53 \times 10^{3}$ cells at $1 \mu \mathrm{M} ; 2.67 \pm 0.58 \times 10^{3}$ cells at $5 \mu \mathrm{M}$; $1.15 \pm 1.03 \times 10^{3}$ cells at $\left.10 \mu \mathrm{M} ; P<0.05\right)$ in the Transwell cell culture chamber assay. Using microarray analysis, 81 genes were down-regulated and 71 genes were up-regulated after curcumin treatment. Below sublethal concentrations of curcumin $(10 \mu \mathrm{M})$, several invasion-related genes were sup-
\end{abstract}

pressed, including matrix metalloproteinase 14 (MMP14; 0.65fold), neuronal cell adhesion molecule (0.54-fold), and integrins $\alpha 6$ (0.67-fold) and $\beta 4$ (0.63-fold). In addition, several heatshock proteins (Hsp) [Hsp27 (2.78-fold), Hsp70 (3.75-fold), and Hsp40-like protein (3.21-fold)] were induced by curcumin. Realtime quantitative reverse transcription-polymerase chain reaction, Western blotting, and immunohistochemistry confirmed these results in both RNA and protein levels. Curcumin (1 to 10 $\mu \mathrm{M})$ reduced the MMP14 expression in both mRNA and protein levels and also inhibited the activity of MMP2, the down-stream gelatinase of MMP14, by gelatin zymographic analysis. Based on these data, it can be concluded that curcumin might be an effective antimetastatic agent with a mechanism of anti-invasion via the regulation of certain gene expressions.
Curcumin, or diferuloylmethane, is a major chemical component of turmeric (Curcuma longa) and is used as a spice to give a specific flavor and yellow color to curry. It is also used as a cosmetic and in some medical preparations (Govindarajan, 1980). Curcumin has been shown to display anticarcinogenic properties in animals, as indicated by its ability to inhibit phorbol ester-induced skin tumors in a mouse model system (Huang

This work was supported by NSC 89-2314-B-002-108 (Taipei, Taiwan, Republic of China).

J.J.W.C. and P.C.Y. contributed equally to this study.

This study has been presented in part at the 94th Meeting of the American Association for Cancer Research; 2003 July 11-15; Washington, DC (abstract no 2766). et al., 1988). In addition to its anticarcinogenic effect, curcumin is also shown to exhibit anti-inflammatory, antiproliferative, antiangiogenic, and antioxidant properties (Aggarwal et al., 2003). These effects of curcumin may be mediated by its inhibitory effect on a host of cell-signaling factors, including AP-1 transcription factor, c-Myc, Egr-1, NF- $\kappa$ B, protein kinase C, epidermal growth factor receptor tyrosine kinase, c-Jun N-terminal kinase, protein tyrosine kinases, protein serine/threonine kinases, and I $\kappa$ B kinase (Huang et al., 1988; Hong et al., 1999; Lin et al., 2000). In our previous study, it was also found that curcumin could inhibit cell cycle progression and induce cell apoptosis by regulating the gene expression of c-myc and bcl-2 (Chen and Huang, 1998).

ABBREVIATIONS: NF- $\kappa$ B, nuclear factor- $\kappa \mathrm{B}$; DMEM, Dulbecco's modified Eagle's medium; PI, propidium iodide; PCR, polymerase chain reaction; EST, expressed sequence tag; IMAGE, Integrated Molecular Analysis of Genomes and their Expression; RTQ-RT-PCR, real-time quantitative reverse transcription-polymerase chain reaction; TBP, TATA box binding protein; HSP, heat shock protein; NCAM, putative neuronal cell adhesion molecule; MMP, matrix metalloproteinase; SOM, self-organizing map; ANOVA, analysis of variance; TOPO, topoisomerase; AP-1, activator protein 1. 
The prognosis of cancer is mainly determined by the invasiveness of tumor cells; the metastasis of cancer cells is one of the major deciding factors in cancer outcome. Although there are already several drugs available to control cancer growth, there are still no drugs presently available that specifically inhibit the metastatic behavior of cancer cells. Curcumin has previously been identified to exhibit antimetastatic activity (Menon et al., 1995, 1999). Oral administration of curcumin at a concentration of $200 \mathrm{nmol} / \mathrm{kg}$ body weight was found to significantly inhibit lung metastasis as evidenced by the reduction in the number of lung tumor nodules $(80 \%)$ and an increase in life span (143.9\%) (Menon et al., 1995). Curcumin treatment $(10 \mu \mathrm{g} / \mathrm{ml}=27.14 \mu \mathrm{M})$ significantly inhibited the invasion of B16F-10 melanoma cells across the collagen matrix of the Boyden chamber (Menon et al., 1999). A previous study also demonstrated that curcumin inhibited angiogenesis in a subcutaneous Matrigel plug model in mice (Thaloor et al., 1998). These results indicate a possible use of curcumin in arresting the metastatic growth of tumor cells, but the mechanism remains unknown.

Metastasis is a complicated multistep process that involves interactions between cancer cells and their surrounding microenvironments. Previously, a series of lung adenocarcinoma cell lines (CL1-0, CL1-1, and CL1-5) with varying degrees of invasiveness was established (Chu et al., 1997). Tracheal graft assays confirmed that cell lines with higher in vitro invasiveness had greater in vivo invasive potential. The CL1-5 cell line exhibited relatively higher invasive ability than the other lung adenocarcinoma cell lines (CL1-0 and CL1-1). Recently, these model cell lines were used to identify invasion-associated genes using cDNA microarray with colorimetric detection (Chen et al., 2001). These data demonstrated that genes related to cell adhesion, motility, angiogenesis, signal transduction, and some other expressed sequence tag genes may play significant roles in the metastastic process.

In this report, the antimetastatic activity of curcumin by the Matrigel invasion assay system was surveyed, and the curcumin-regulated gene expression in the lung adenocarcinoma cell line (CL1-5) was further characterized using cDNA microarray technique. According to these findings, curcumin may have potential as a new antimetastasis drug. By analyzing the curcumin-regulated genes in antimetastasis and comparing the invasion-associated genes that have already been identified (Chen et al., 2001), the genetic control of cancer cell metastasis could be further explored and a pathway for new anticancer drug development could be established.

\section{Materials and Methods}

Cell Lines. The human lung adenocarcinoma cell line with highly invasive capacities (CL 1-5) was grown in DMEM medium with $10 \%$ fetal bovine serum at $37^{\circ} \mathrm{C}, 20 \% \mathrm{O}_{2}$, and $5 \% \mathrm{CO}_{2}$, as described previously with some modification (Chu et al., 1997).

Cell Viability and Apoptosis. To examine the antiproliferative effects of curcumin (Sigma, St. Louis, MO), the CL1-5 cells were treated with different concentrations of curcumin $(0,1,5,10$, and 20 $\mu \mathrm{M})$ for $24 \mathrm{~h}$. Cell viability was assessed by the trypan blue exclusion (Chen and Huang, 1998) and confirmed by the uptake of 3-(4,5dimethyl-thiazol-2yl)-2,5-diphenyl tetrazolium bromide assays (Chen et al., 2002b).

Apoptotic cells were detected by both PI and Annexin V labeling as described previously (Chen et al., 2002a). Double-labeling was performed at $37^{\circ} \mathrm{C}$ as follows: PI $(50 \mu \mathrm{g} / \mathrm{ml})$ and Annexin V $(2 \mu \mathrm{g} / \mathrm{ml})$ were added to the culture medium for $2 \mathrm{~h}$, then the staining was immediately examined on the Leica DMRA fluorescence microscope (Leica, Wetzlar, Germany). Annexin V staining is an established biochemical marker of apoptosis (Koopman et al., 1994; Vermes et al., 1995). The partial loss of membrane integrity or functionality is a useful criterion for distinguishing apoptotic from necrotic and living cells.

Matrigel Invasion Assay. Invasiveness of the CL1-5 cells was examined by using the membrane invasion culture system as described previously with some modification (Chen et al., 2001). Briefly, Transwell membranes (8- $\mu \mathrm{m}$ pore size, $6.5-\mathrm{mm}$ diameter; Corning Costar Corporation, Cambridge, MA) were coated with Matrigel (2.5 mg/ml; BD Biosciences Discovery Labware, Bedford, MA) and dry coatings were reconstituted in DMEM for 1 to $2 \mathrm{~h}$ before cell passage. Cells were trypsinized, centrifuged, and resuspended at $10^{7}$ cells $/ \mathrm{ml}$ in DMEM containing 10\% FBS. Cells were seeded onto the upper wells of precoated transwells. Lower wells of the transwells contained the same medium. After a 24-h incubation, membranes coated with Matrigel were swabbed with a Q-tip, fixed with methanol, and stained with crystal violet before cell counting under phasecontrast microscopy.

Biotinylated Probe Preparation and Microarray Hybridization. Five micrograms of mRNAs derived from CL1-5 treated with or without curcumin $(1,5,10$, and $20 \mu \mathrm{M})$ were labeled with biotin during reverse transcription as described in previous reports (Hong et al., 2000; Chen et al., 2001, 2002a). The microarrays (which measured $18 \times 27 \mathrm{~mm}$ ) carrying 9600 PCR-amplified cDNA fragments were prepared on nylon membranes by an arraying machine (Wittech, Taipei, Taiwan). The 9600 nonredundant EST clones were Integrated Molecular Analysis of Genomes and their Expression (IMAGE) human cDNA clones, each representing a putative gene cluster with an assigned gene name in the Unigene clustering. All hybridization experiments were performed in triplicate. The details of probe preparation, hybridization, and color development have also been described previously (Chen and Huang, 1998; Chen et al., 2001). The microarray images were scanned and digitized using a flatbed scanner (PowerLook 3000; UMAX, Taipei, Taiwan). The scanner provided 3000 dpi resolution and was suitable for larger arrays, such as arrays of 9600 elements. The microarray images were processed by commercial image processing programs to convert the true-color images into gray-scale images, and the image analysis and spot quantification were done with the use of the GenePix 3.0 program (Axon Instruments, Union City, CA).

Real-Time Quantitative RT-PCR. To confirm the expression patterns of up-regulated or down-regulated genes after curcumin treatment, the selected cell proliferation- and metastasis-related genes were chosen for further analysis using real-time quantitative reverse transcription-PCR (RTQ-RT-PCR) in a 96-well format. The detailed procedure has been described previously (Chen et al., 2003). Briefly, all reactions were carried in $50-\mu$ l volumes containing $25 \mu \mathrm{l}$ of SYBR Green PCR master mix (Applied Biosystems Inc., Foster City, CA). The TATA box binding protein (TBP) was quantified as an internal control using the primers described in a previous report (Chen et al., 2003). DNA amplification was carried out using a ABI 7700 Sequence Detection System (Applied Biosystems), and the detection was carried out by measuring the binding of the fluorescence dye SYBR Green I to double-stranded DNA. After cycling, relative quantitation of tested gene cDNA against the internal control, TBP, was possible using a $\Delta \mathrm{C}_{\mathrm{T}}$ method. An amplification plot of the fluorescence signal versus cycle number was drawn. In the initial cycles of PCR, there was little change in fluorescence signal. This defined the baseline for the amplification plot. An increase in fluorescence above the baseline indicated the detection of accumulated PCR product. A fixed fluorescence threshold was set above the baseline in the exponential phase of the PCR. The parameter $\mathrm{C}_{\mathrm{T}}$ (threshold cycle) was defined as the fractional cycle number at which the fluorescence 
passed the fixed thresholds. The differences $\left(\Delta \mathrm{C}_{\mathrm{T}}\right)$ between the mean values in triplicate samples of tested gene cDNA and those of TBP were calculated by Microsoft Excel and the relative quantitation value was defined as $2-\Delta \mathrm{CT} \times K$, where $K$ is a constant).

Western Blot Analysis and Immunohistochemistry. Western blotting and immunohistochemistry were used to confirm the differentially expressed genes after curcumin treatment. The detailed procedures were as described previously (Chen et al., 2002b). The primary antibodies for Hsp27, Hsp40, Hsp70, topoisomerase I, topoisomerase II $\alpha$, neural cell adhesion molecule (NCAM), AXL tyrosin kinase, and androgen receptor were purchased from Santa Cruz Biotechnology, Inc. (Santa Cruz, CA) and primary antibody for MMP14 (MT1-MMP) was purchased from Chemicon (Temecula, CA). The dilutions of antibodies were 1:1000 for Western blotting and 1:100 for immunohistochemistry. For Western blot, $\alpha$-tubulin was used as an internal control. Membranes were developed using the substrate of alkaline phosphatase, nitro blue tetrazolium/5-bromo-4chloro-3-indolyl phosphate. The signal intensities for the proteins were quantified using a densitometer (Imagemaster V-DS; Amersham Biosciences, Piscataway, NJ). Fluorescein isothiocyanate-conjugated (for MMP14, Hsp40, and Hsp 70) and tetramethylrhodamine $\mathrm{B}$ isothiocyanate-conjugated (for NCAM and topoisomerase II $\alpha$ ) 2nd antibodies (Santa Cruz, Biotech Inc., CA) were used for immunohistochemistry. 4,6-Diamidino-2-phenylindole or propidium iodide was used as counter-staining for cell nuclei. The stained cells were then examined by fluorescence microscopy (DM-RA; Leica, Wetzlar, Germany).

Zymographic Analysis. Curcumin effects on MMP2, MMP9, and MMP14 gelatinolytic activity were assayed by gelatin zymography as described previously with some modification (Dell'Aica et al., 2002). Briefly, after the curcumin treatment, the media were collected (for MMP2 and -9) and the cells were harvested and re-suspended in 1\% digitonin, $0.15 \mathrm{M} \mathrm{NaCl}, 20 \mathrm{mM}$ HEPES, $\mathrm{pH} 7.0$ (DIG buffer), and incubated for $2 \mathrm{~h}$ at $4^{\circ} \mathrm{C}$ with gentle motion. The sample was then centrifuged for $5 \mathrm{~min}$ at $1200 \mathrm{~g}$ to collect the cell membrane proteincontaining supernatant (for MMP14). Without heating, samples (medium and membrane protein-containing supernatant) underwent electrophoresis in $7.5 \%$ polyacrylamide gels containing $0.1 \%$ gelatin in the presence of SDS under nonreducing conditions. After electrophoresis, the gels were washed twice for 15 min with $2.5 \%$ Triton $\mathrm{X}-100$ and incubated overnight at $37^{\circ} \mathrm{C}$ in $50 \mathrm{mM}$ Tris- $\mathrm{HCl}, 200 \mathrm{mM}$ $\mathrm{NaCl}, 10 \mathrm{mM} \mathrm{CaCl}_{2}, \mathrm{pH} 7.4$ (buffer 1). The gels were then stained for 30 min with $30 \%$ methanol $/ 10 \%$ acetic acid containing $0.5 \%$ Coomassie Brilliant blue R-250 and destained in the same solution without dye; clear bands represent areas of gelatinolysis on the blue background. Digestion bands were quantified using the densitometer (Imagemaster V-DS; Amersham Biosciences).

Transcriptional Regulation Assay. NF- $\kappa \mathrm{B}$ transcriptional activity was determined by reporter gene assay, as in our previous study (Chen et al., 2003). Briefly, the CL1-5 cells $\left(5 \times 10^{4}\right.$ cells/well) were seeded into six-well plates and allowed to grow for $24 \mathrm{~h}$. The cells were cotransfected with NF- $\kappa$ B-binding domain luciferase (pGL2-4× AGGGGACTTTCC-luciferase; a gift from Dr. Shuang-En Chung, National Health Research Institutes) and pSV- $\beta$-galactosidase constructs (to normalize the transfection efficiency) (Promega, Madison, WI) by LipofectAMINE method (Jain and Magrath, 1991). The transfected cells were treated with different concentrations of curcumin for $24 \mathrm{~h}$. Cell lysate was harvested to assay the luciferase activity according to the Tropix Luciferase Assay kit (Tropix). All of the experiments included nontransfection and vector alone because negative controls were performed in triplicate and normalized with both transfection efficiency and protein quantity.

Statistical Analysis. Cluster analysis was performed to identify curcumin-regulated genes on the microarray. Gene expression data obtained from the microarray experiments were processed and normalized using the protocol and program described by Iyer et al. (1999). Genes were clustered into groups on the basis of expression profiles by the self-organizing maps (SOMs) algorithm as described by Tamayo et al. (1999) and previous studies conducted by the authors (Chen et al., 2001). After cluster analysis by the SOM method, genes whose expression profiles correlated either positively or negatively with the concentrations of curcumin were identified. Genes whose expression correlated with the invasiveness of cell lines were also grouped into categories by their putative functions on the basis of literature reports (Table 1 ).

A repeated-measures ANOVA was performed to determine any significant differences between the invasive cells and mRNA or protein expression intensities. Data from at least three independent experiments were analyzed by ANOVA (Excel, Microsoft, Taipei, Taiwan, Republic of China) to determine any significant difference.

\section{Results}

Low Concentrations of Curcumin Can Suppress Cell Invasion. The number of viable cells after curcumin treatment was estimated using a hemocytometer with the trypan blue dye exclusion test. Exposure of CL1-5 cells to curcumin $(0,1,5,10,20,50$, and $60 \mu \mathrm{M})$ influenced the cell viability of CL1-5 cells in a concentration-dependent manner $(92.3 \pm$ $6.1 \%$ at $10 \mu \mathrm{M}, 70.1 \pm 7.3 \%$ at $20 \mu \mathrm{M}$, and $29.6 \pm 2.8 \%$ at 30 $\mu \mathrm{M}, P<0.05$, ANOVA) (Fig. $1 \mathrm{~A}$ ). The $\mathrm{IC}_{50}$ of curcumin was $33.2 \pm 3.7 \mu \mathrm{M}$ in CL1-5 cell viability $(n=4)$. Furthermore, curcumin concentration-dependently $(\geq 20 \mu \mathrm{M}$ in CL1-5 cells) induced cell apoptosis, as examined by flow cytometry and fluorescence microscopy with Annexin-V/PI (Fig. 1B). These results indicate that curcumin exhibited antiproliferative activity and induced cell apoptosis in CL1-5 cells.

Metastasis is highly dependent on tumor cell invasion. Therefore, the effect of curcumin on CL1-5 was determined. For the invasion assay, CL1-5 cells were penetrated through a uniform layer of Matrigel, which consists of collagen type IV, heparan sulfate proteoglycan, entactin, and laminin. The results showed that curcumin ( 1 to $10 \mu \mathrm{M}$ ) could significantly inhibit cell invasion of CL1-5 cells $(56.0 \pm 16.1 \%$ at $1.0 \mu \mathrm{M}$, $P<0.05)$ in a concentration-dependent manner with an $\mathrm{IC}_{50}$ value of $1.2 \pm 0.3 \mu \mathrm{M}$ (Fig. 1A). It also demonstrated that curcumin could inhibit cell invasion at a concentration lower than the dose that induced cell apoptosis $(20 \mu \mathrm{M})$ (Fig. 1). According to these results, concentrations of $0,1,5,10$, and $20 \mu \mathrm{M}$ were used for microarray analysis and the following experiments.

Microarray Analysis of Gene Expression of Lung Cancer Cells after Treatment with Curcumin. Biotinlabeled probe derived from CL1-5 cell line mRNA treated with or without curcumin were hybridized to microarrays, with 9600 putative genes to profile the curcumin-related gene expression patterns. To identify the curcumin-related anti-invasive genes, cluster analysis was performed on the expression profiles of the curcumin-treated CL1-5 cells at concentrations of $0,1,5,10$, and $20 \mu \mathrm{M}$. Of the 9600 putative genes, only 416 genes had statistically significant expression differences between normal and curcumin-treated cells.

After SOM clustering, these genes were grouped into nine clusters. Two clusters of expression profiles with descending trend containing 81 genes and two for ascending trend containing 71 genes were selected from these nine clusters. To avoid confusion of negative values in expression patterns, the scale value of normalization, from -1 to +1 , was shifted to a positive value by adding 1 for each data, which made the scale value become 0 to +2 . Figure $2 \mathrm{~A}$, left, contains two clusters of gene expression profiles that were inhibited by 
TABLE 1

Curcumin-regulated genes

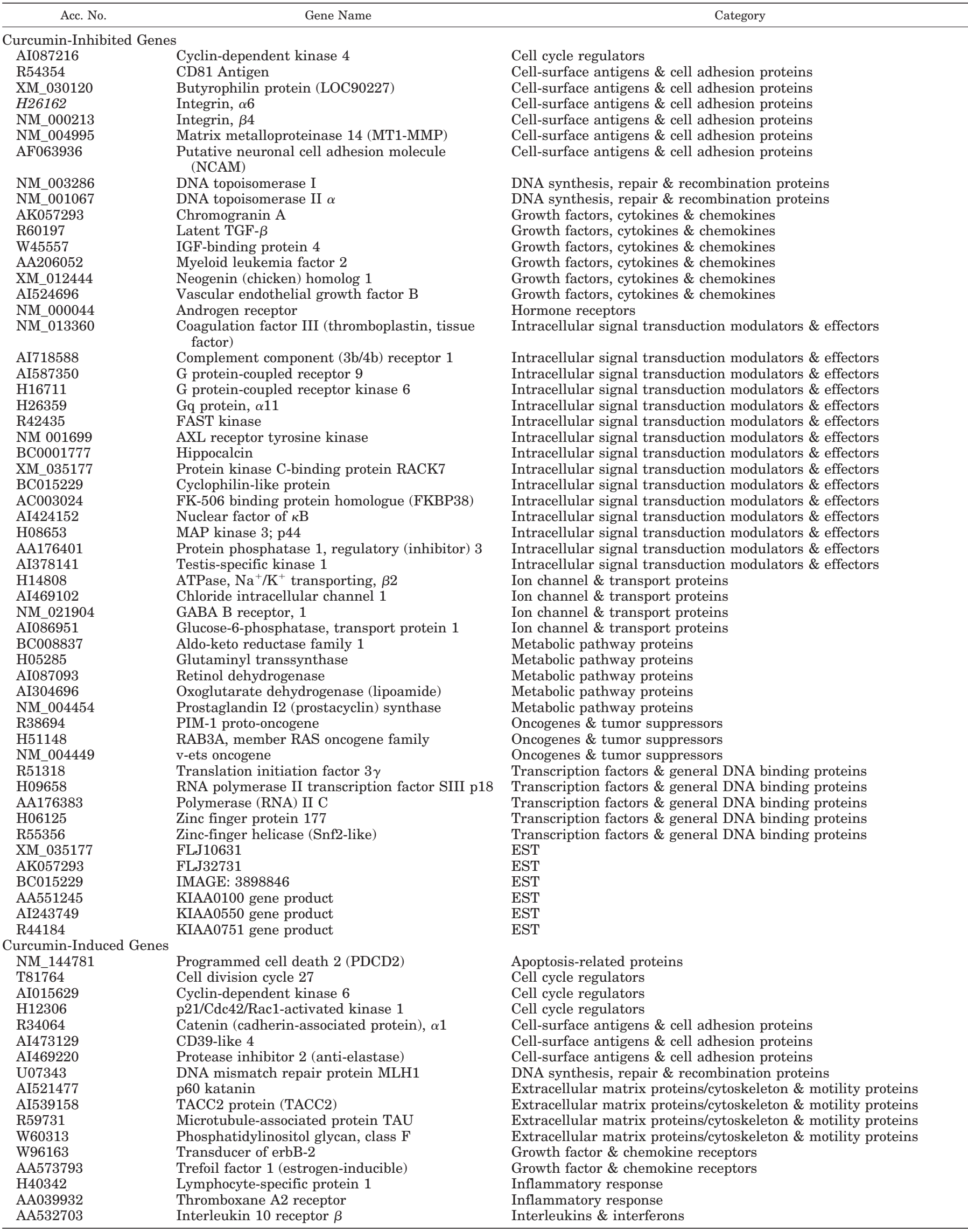


curcumin. Each of the two clusters contained expression profiles of 44 and 37 genes. Figure 2B, left, shows the expression profiles of the two clusters that were induced by curcumin. Each of these contained 24 and 47 genes.

All of the gene expression profiles in these clusters were rearranged by hierarchical cluster analysis with the average linkage method (Iyer et al., 1999; Chen et al., 2001), and the expression levels were gray-scale encoded as shown at the right of each SOM cluster (Fig. 2, A and B). Figure 2A shows the levels of gene expression from high (white) to low (black), indicating that these genes were down-regulated by curcumin; Fig. 2B shows the gene expression levels from low (black) to high (white), indicating these genes were up-regulated by curcumin.

Categories of Curcumin-Regulated Genes. These genes clustered in Fig. 2 were grouped into several categories on the basis of their cellular functions (Table 1). In Table 1, these categories included cell cycle regulators (such as cyclindependent kinase 4), cell-surface antigens and cell adhesion proteins (such as integrins $\alpha 6$ and $\beta 4$, MMP14, and NCAM), DNA synthesis, repair, and recombination proteins (such as DNA topoisomerase I and II $\alpha$ ), growth factors, cytokines, and chemokines (such as vascular endothelial growth factor-B), hormone receptors (such as androgen receptor), intracellular signal transduction modulator and effectors (such as G-protein coupled receptor kinase 6, AXL receptor tyrosine kinase, and FAST kinase), ion channel and transport proteins (such as ATPase, $\mathrm{Na}^{+} / \mathrm{K}^{+}$transporting protein $\beta 2$ ), metabolic pathway proteins (such as glutaminyl-trans synthase), oncogenes and tumor suppressors (such as v-ets), transcription factors and general DNA binding proteins (such as zinc finger pro- tein 177), apoptosis-related proteins (such as programmed cell death 2), inflammatory response proteins (such as thromboxane A2), interleukins and interferons (interleukin 6 and 10 receptor $\beta$ ), extracellular matrix proteins (such as microtubule-associated protein, TAU), stress response proteins (such as Hsp40-like protein and Hsp70), and EST genes (such as FLJ10631, FLJ 32731, and IMAGE3898846).

Verification of Curcumin Regulated Genes Identified by cDNA Microarray by RTQ-RT-PCR, Western Blot, and Immunohistochemistry. To substantiate the results of the microarray studies, RTQ-RT-PCR was performed to assess the mRNA expression of 16 of the curcuminregulated genes (10 for down-regulation and six for up-regulation). Western blotting and immunohistochemistry were used to assess the protein expression levels and localization of several of the gene products based on the availability of antibodies.

As shown in Fig. 3, A and B, the chosen genes, which were confirmed with RTQ-RT-PCR, were compared to obtain the results of different expression ratios in microarray analysis. These results showed that the mRNA levels of DDIT3 (3.82 \pm 0.38-fold; increased), GRM7 (5.91 \pm 0.49-fold; increased), Hsp27 (3.25 \pm 0.41-fold; increased), Hsp40-like protein (2.82 \pm 0.37-fold; increased), and Hsp70 (3.32 \pm 0.43-fold; increased) were confirmed to be up-regulated; and GABBR1 (2.54 \pm 0.02-fold; decreased), FLJ32731 (2.15 \pm 0.10-fold; decreased), MMP14 (MT1-MMP) (2.01 \pm 0.07-fold; decreased), NCAM (1.92 \pm 0.06-fold; decreased), IMAGE clone 3898846 (1.91 \pm 0.05-fold; decreased), FLJ10831 (1.87 \pm 0.07-fold; decreased), TOPO I (1.34 \pm 0.12-fold; decreased), TOPO II $\alpha$ (1.65 \pm 0.06-fold; decreased), v-ets oncogene

TABLE 1 Continued

\begin{tabular}{|c|c|c|}
\hline Acc. No. & Gene Name & Category \\
\hline AI074123 & Interleukin 6 & Interleukins \& interferons \\
\hline AI304505 & Cryptochrome 2 (photolyase-like) & Intracellular signal transduction modulators \& effectors \\
\hline $\mathrm{R} 43329$ & Protein phosphatases PP1 regulator & Intracellular signal transduction modulators \& effectors \\
\hline AI654758 & fer (fps/fes related) tyrosine kinase & Intracellular signal transduction modulators \& effectors \\
\hline H06479 & MacMarcks & Intracellular signal transduction modulators \& effectors \\
\hline $\mathrm{R} 43220$ & Cdc14B2 phosphatase & Intracellular signal transduction modulators \& effectors \\
\hline $\mathrm{R} 20770$ & Syntaxin 4 binding protein UNC-18c & Intracellular signal transduction modulators \& effectors \\
\hline R37588 & RalGDS-like 2 (RGL2) & Intracellular signal transduction modulators \& effectors \\
\hline AA114872 & Iron-responsive element binding protein 1 & Intracellular signal transduction modulators \& effectors \\
\hline H11973 & Potassium channel protein KV2.1 & Ion channel \& transport proteins \\
\hline AA961937 & Cytochrome c oxidase subunit VIIb & Metabolic pathway proteins \\
\hline $\mathrm{R} 41989$ & C-1-Tetrahydrofolate synthase C & Metabolic pathway proteins \\
\hline $\mathrm{AI} 263472$ & Serine palmitoyltransferase, subunit I & Metabolic pathway proteins \\
\hline R37570 & Ubiquitin conjugating enzyme (UbcH8) & Metabolic pathway proteins \\
\hline H15721 & Phosphoribosyl pyrophosphate synthetase 2 & Metabolic pathway proteins \\
\hline U92458 & Glutamate receptor, metabotropic 7 (GRM7) & Neurotransmitter receptors \\
\hline AA121523 & Atrial natriuretic factor precursor & Stress response proteins \\
\hline AA514500 & ATX1 (antioxidant protein 1) & Stress response proteins \\
\hline $\mathrm{R} 82347$ & Glutathione $S$-transferase $\pi$-1 & Stress response proteins \\
\hline XM_058528 & DNA-damage-inducible transcript 3 (DDIT3) & Stress response proteins \\
\hline NM_005345 & Heat shock $70-\mathrm{kDa}$ protein1A (HSP70-1A) & Stress response proteins \\
\hline AB020027 & Heat shock 27-kDa protein (HSP27) & Stress response proteins \\
\hline H81637 & Putative DDB p127-associated protein & Stress response proteins \\
\hline $\mathrm{BC} 001144$ & ER-associated DNAJ (HSP40) & Stress response proteins \\
\hline NM_003932 & $\mathrm{p} 48$, Hsp70 interacting protein & Stress response proteins \\
\hline R599̄900 & E2F transcription factor 4, p107/p130-binding & Transcription factors \& general DNA binding proteins \\
\hline AA080948 & Eukaryotic translation initiation factor $4 \mathrm{E}$ & Transcription factors \& general DNA binding proteins \\
\hline XM_028204 & NFKB1 & Transcription factors \& general DNA binding proteins \\
\hline N20235 & Pre-B cell leukemia transcription factor- 2 & Transcription factors \& general DNA binding proteins \\
\hline AI138789 & EST & 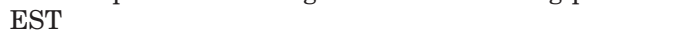 \\
\hline AI186064 & EST & EST \\
\hline AI125328 & EST & EST \\
\hline W90164 & IMAGE:418150 & EST \\
\hline AI284062 & KIAA0020 gene product & EST \\
\hline AA280281 & KIAA0171 gene product & EST \\
\hline
\end{tabular}


(1.39 \pm 0.13-fold; decreased), and LOC90227 (1.33 \pm 0.12fold; decreased) were down-regulated at $24 \mathrm{~h}$ after curcumin treatment (10 $\mu \mathrm{M})$ by RTQ-RT-PCR in CL1-5 cells.

Similarly, Western blotting confirmed that stress-response proteins (Hsp27, Hsp40-like protein, and Hsp70), were increased after curcumin treatment (Fig. 4). The cell invasionrelated factors (MMP14 and NCAM) and proliferative factors (TOPO-I and II $\alpha$ ) were all down-regulated in both mRNA and protein levels after curcumin treatment in a concentrationdependent manner $(0,1,5,10$, and $20 \mu \mathrm{M})$ (Fig. 3 and 4). As indicated by the immunohistochemical staining in Fig. 5, the protein expression levels of NCAM, MMP14 (MT1-MMP), and TOPO-II $\alpha$ were highly expressed in CL1-5 cells without curcumin treatment. The NCAM and MMP14 (MT1-MMP) proteins were localized on the cell membrane, whereas TOPO-II $\alpha$ was located in the cell nuclei with granular distribution. All of these proteins were reduced by curcumin in a concentration-dependent manner (1, 5, and $10 \mu \mathrm{M}$ curcumin). In particular, the protein expression of TOPO-II $\alpha$ was not only down-regulated but also lost the granulated localization in cell nuclei after curcumin treatment in CL1-5 cells (Fig. 5). On the other hand, the expression of HSPS

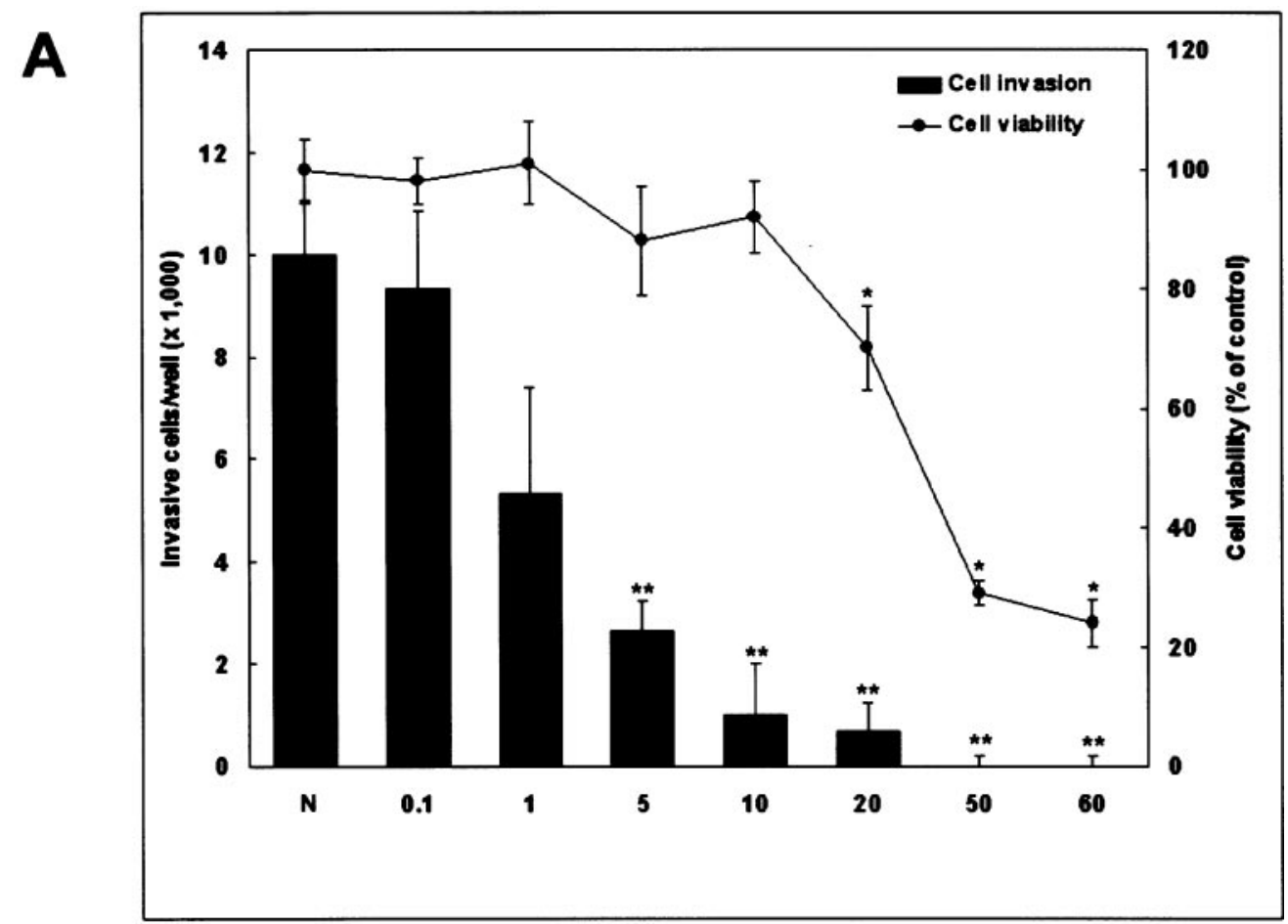

B

$\mathbf{N}$
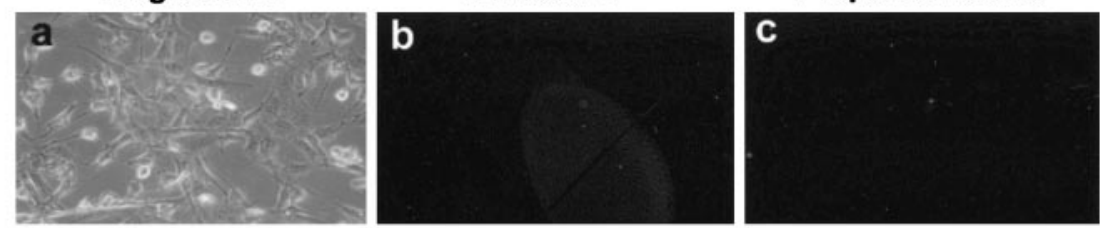

$10 \mu \mathrm{M}$

Curcumin
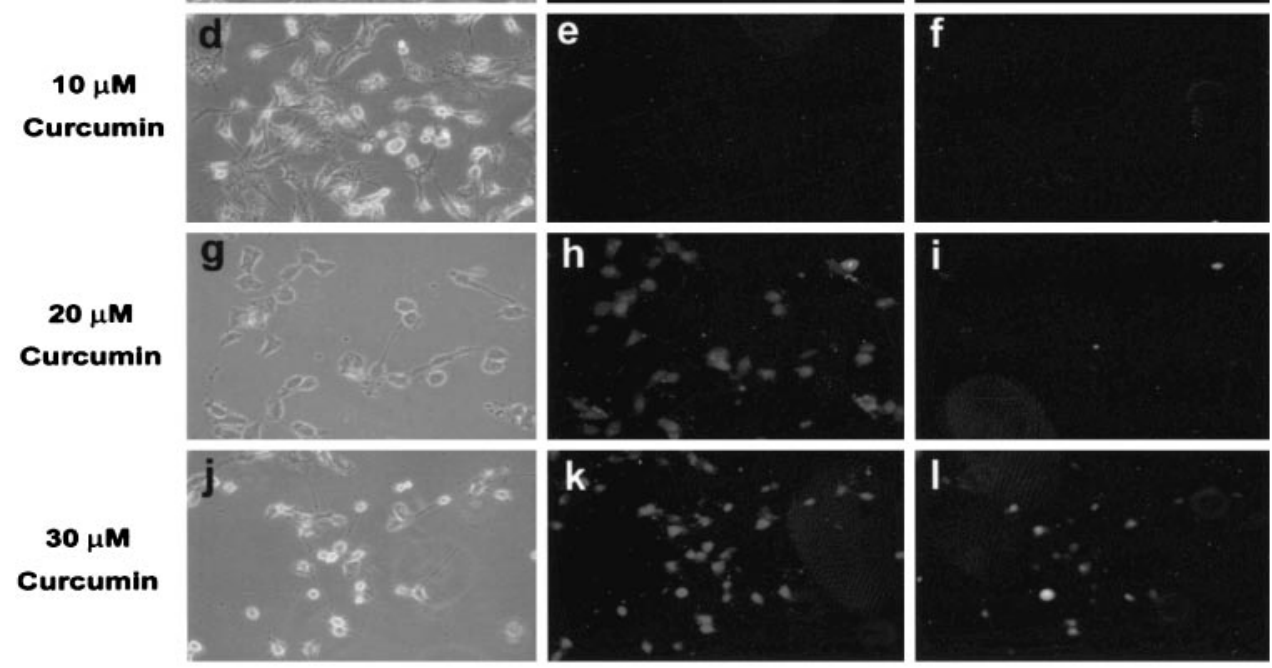
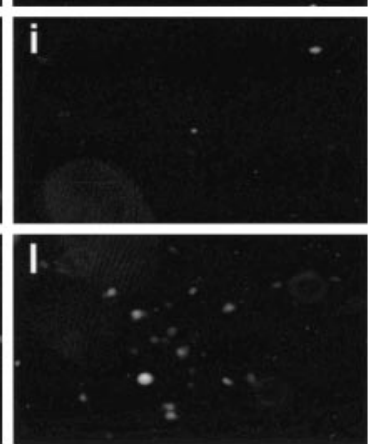

Fig. 1. Effects of curcumin on CL1-5 cell viability, cell invasion, and apoptosis after $24 \mathrm{~h}$ of incubation. A, the effect of curcumin $(0,1,5,10,20,50$, and $60 \mu \mathrm{M})$ on the cell viability of CL1-5 cells was expressed as a percentage of the normal control values (\% of control). Each point and vertical line represents the mean \pm S.E.M. $(n=5) . *, P<0.05$ compared with normal control values in the absence of curcumin $(\mathrm{N})$. The bars present the in vitro invasion activity of CL1-5 cells incubated with or without different concentrations of curcumin $(0,1$, $5,10,20,50$, and $60 \mu \mathrm{M})$ for $24 \mathrm{~h}$. Bars, average number of cells which invaded through the matrix gel. Each column represents the mean \pm S.E.M. $(n=5)$. **, $P<0.05$, compared with normal control values in the absence of curcumin $(\mathrm{N})$. B, curcumin-induced morphological change and apoptosis in CL1-5 cells. CL1-5 cells untreated (a, b, and $\mathrm{c}$ ), or treated with $10 \mu \mathrm{M}$ curcumin (d, e, and f), $20 \mu \mathrm{M}$ curcumin ( $\mathrm{g}, \mathrm{h}$, and $\mathrm{i}$ ), or $30 \mu \mathrm{M}$ curcumin (j, k, and l) were performed using PI and Annexin V labeling as described under Materials and Methods. Shown are bright-field views (BF; a, d, g, and j) and fluorescence microscopic observation with annexin-V (Annexin-V; $b$, $\mathrm{e}, \mathrm{h}$, and $\mathrm{k}$ ) or propidium iodide (PI; c, $\mathrm{f}, \mathrm{i}$, and l) staining. Similar results were obtained in four additional experiments using independent CL1-5 cell preparations, original $\times 400$. 
(Hsp27, Hsp40, and Hsp70) were increased and the proteins were translocated from the cytosol to nuclei after curcumin treatment (Fig. 5).

Effect of Curcumin on MMP Activity. As previously reported, it has been shown that MMP14 might be associated with the tissue inhibitor of metalloproteinase 2, both acting together as a receptor for pro-MMP2 and leading to the cleavage of the zymogen in several tumor systems (Fillmore et al., 2001). The expression of MMP14 was significantly down-regulated after curcumin treatment ( 1 to $10 \mu \mathrm{M}$; Fig. 6 ). Furthermore, the effects of curcumin on MMP2 gelatinolytic activity were studied using the zymographic analysis. The conditioned medium of CL1-5 cells produced clear bands of degradation in the gelatin zymography (Fig. 6, Control). Significantly, curcumin showed the inhibitory effect of MMP2 (both in pro-MMP2 and MMP2, gelatinase A) activity by reducing its gelatinolytic activity, whereas the MMP9 (gelatinase B) activity (Fig. 6) and MMP14 (data not shown) were not significantly influenced by curcumin.

NF- $\kappa$ B Transcriptional Activity Was Inhibited by Curcumin. The NF- $\kappa$ B transcriptional activity was assessed by luciferase reporter gene assay. The luciferase activity in CL1-5 cells after curcumin treatment was significantly suppressed $(86.5 \pm 21.5 \%$ at $5 \mu \mathrm{M}$ curcumin, $P>$ $0.05 ; 42.4 \pm 8.2 \%$ at $10 \mu \mathrm{M}$ curcumin, $P<0.05$, compared with control). The mock-transfected and nontransfected control cells reveled no response in luciferase activity assay (Fig. 7).

A
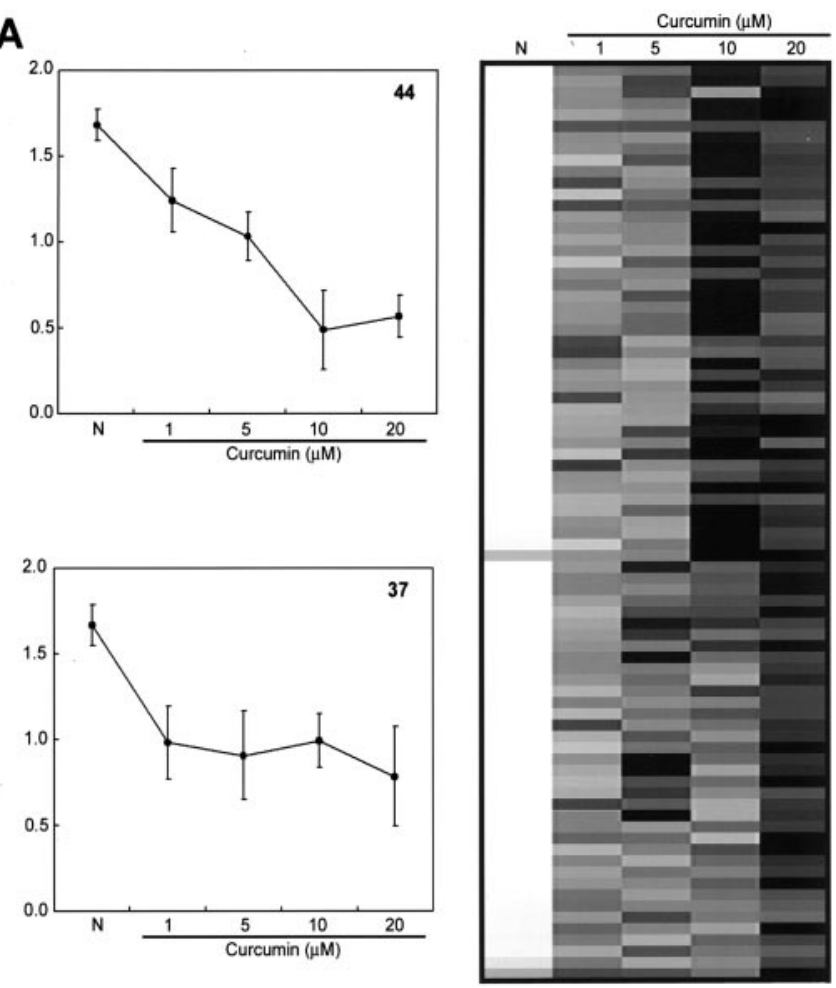

B
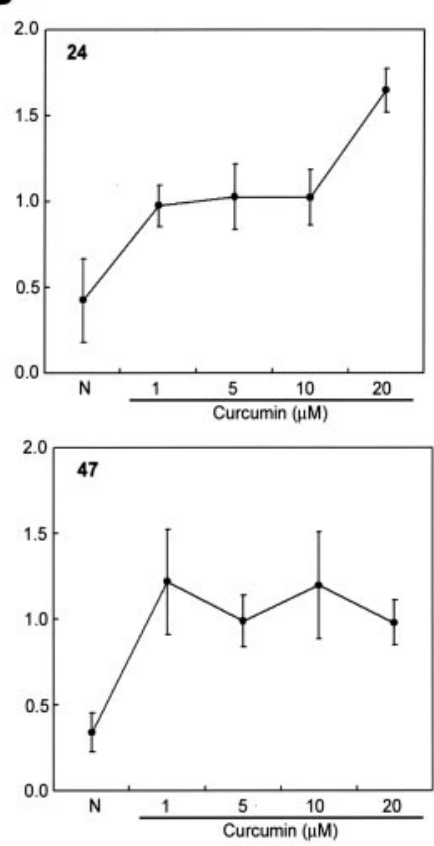

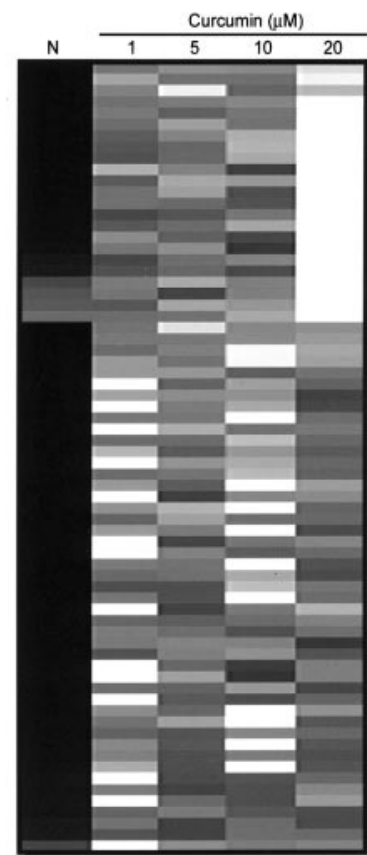

$\begin{array}{lllll}0.0 & 0.5 & 1.0 & 1.5 & 2.0\end{array}$

Fig. 2. Cluster analysis of expression profiles of CL1-5 cells treated with different concentrations of curcumin $(0,1,5,10$, and $20 \mu \mathrm{M})$. A, the genes with descending trend after curcumin treatment. Left, SOM clustering. Two clusters were selected from nine clusters. The number of genes in each cluster is indicated at the corner of each panel, and each cluster was represented by the centroid. Right, hierarchical clustering. All the genes derived from the two descending trend SOM clusters (comprising 44 and 37 genes) were clustered by the average linkage method, and the cluster image shows the trend of gene expression levels with $(1,5,10$, and $20 \mu \mathrm{M})$ or without $(\mathrm{N})$ curcumin treatment. (B) The genes with ascending trend after curcumin treatment. B, left, SOM clustering. Right, hierarchical clustering. 
2002). In the present study, CL1-5 cells exhibit high levels of expression MMP14 (MT1-MMP) and were down-regulated after curcumin treatment.

MMP-2 (gelatinase A) is believed to be of crucial importance in processes requiring basement membrane disruption, such as tumor invasion and metastasis (Bergman et al.,
2003). Overexpression of MMP14 mRNA was reported in tumoral tissues and correlated to the activation of MMP2 in brain, head and neck, breast, and gastrointestinal cancers (Théret et al., 1998). In the present study, the gelatinolytic activity of MMP2 could be inhibited by curcumin. This might be associated as well with the down-regulation of MMP14

A

Microarray
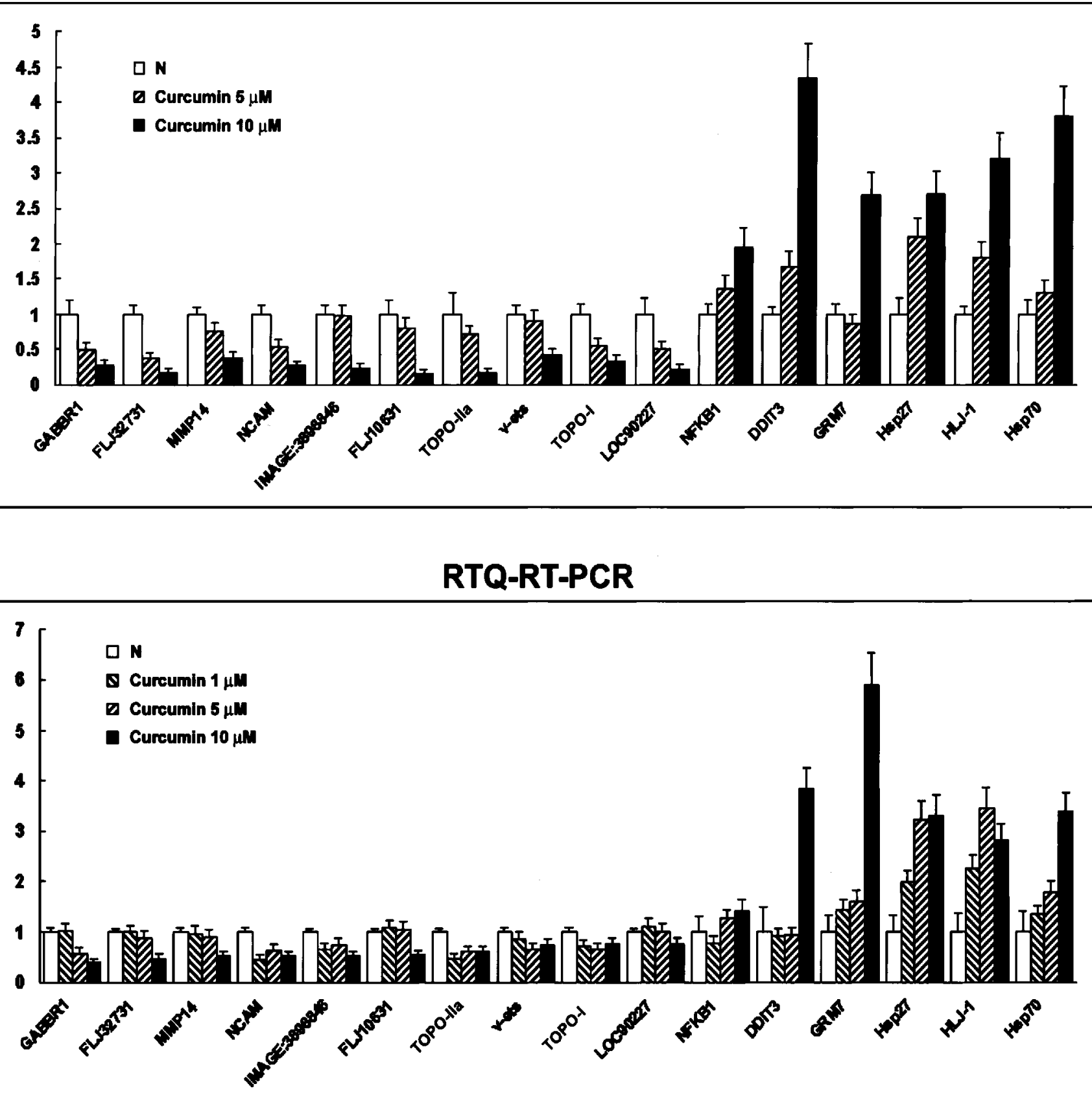

Fig. 3. Comparison of the data of microarray analysis with real time quantitative RT-PCR. A, microarray analysis. The -fold changes of curcuminregulated genes compared with untreated controls were shown by cDNA microarray analysis. Each column represents the mean of-fold \pm S.E.M. $(n=$ 3 ). ${ }^{*}, P<0.05$, compared with normal control values in the absence of curcumin (N). B, RTQ-RT-PCR confirmed commonly up-regulated (six genes) or down-regulated (10 genes) by curcumin in CL1-5 cells. The -fold change was displayed as relative to normalized normal CL1-5 cells without curcumin treatment $(n=3)$. *, $P<0.05$. GABBR1, $\gamma$-aminobutyric acid B receptor 1; FLJ32731 (EST); MMP14 (MT1-MMP) matrix metalloproteinase 14; NCAM, putative neuronal cell adhesion molecule; IMAGE 3898846 (EST); FLJ10631 (EST); TOPO II $\alpha$, topoisomerase II $\alpha$; TOPO I, topoisomerase I; v-ets (oncogene); LOC90227 (EST); NFKB1, nuclear factor of $\kappa$ light polypeptide gene enhancer in B-cells 1 (p105); DDIT3, DNA-damage-inducible transcript 3; GRM7, glutamate receptor metabotropic 7; Hsp27, 27-kDa heat shock protein; HLJ-1, 40-kDa heat shock protein-like protein; Hsp70, $70-\mathrm{kDa}$ heat shock protein. 
expression by curcumin. Most of the MMP genes inducible by extracellular stimuli (MMP1, -3, -7, -9, -10, and -13) harbor an AP-1 binding site in the proximal promoter that could be inhibited by curcumin (Onodera et al., 2002). Therefore, the results of microarray analysis are reasonable in that that curcumin could inhibit MMP7 and MMP10 gene expression. However, MMP14 gene does not contain AP-1 elements (Vi- hinen and Kahari, 2002). The mechanism whereby curcumin could regulate MMP14 (MT1-MMP) expression might be an AP-1 independent pathway, but this requires further substantiation.

Cell adhesion molecules have been demonstrated to play important roles in tumor metastasis (Skubitz, 2002). Subsequent to cDNA microarray screening, several adhesion mol-
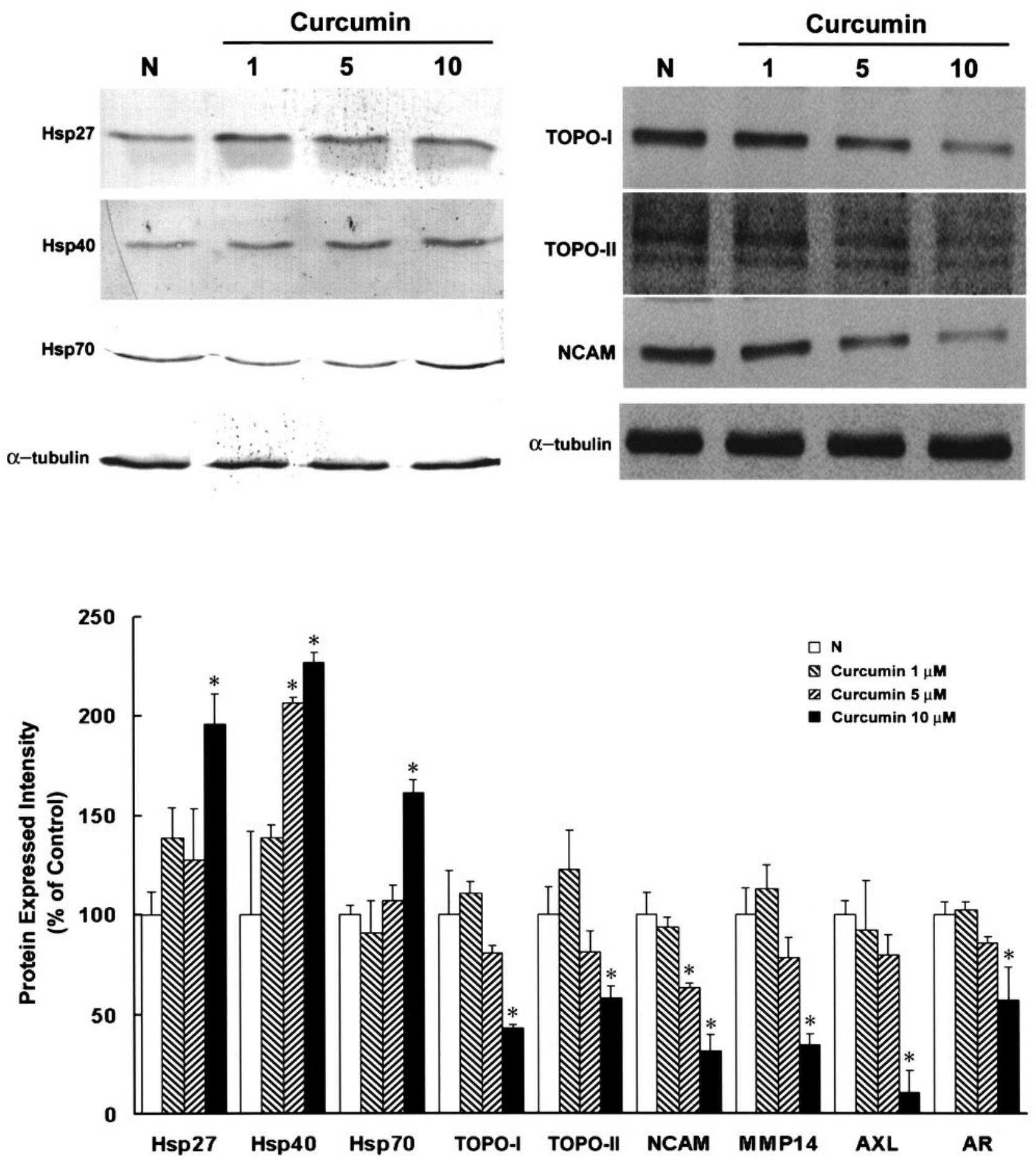

Fig. 4. Western blotting analysis. A, Western blotting confirmed commonly up-regulated or down-regulated by curcumin in CL1-5 cells. The protein levels of Hsp27, -40, and -70 were increased significantly, whereas the $\alpha$-tubulin, the internal control, showed no difference in the expression level. The TOPO-I, TOPO-II $\alpha$, NCAM, MMP14 (MT1-MMP), AXL tyrosine kinase, and androgen receptor (AR) were all concentration-dependently down-regulated by curcumin $(1,5$, and $10 \mu \mathrm{M})$. Similar results of the blotting images were obtained in four additional experiments using independent CL1-5 cell preparations. B, the data on the bar chart were expressed as a percentage of the normal control values (\% of control). Each point with a vertical line represents the mean \pm S.E.M. $(n=5){ }^{*}, P<0.05$, compared with normal control values in the absence of curcumin $(\mathrm{N})$. 
ecules that were down-regulated by curcumin have been identified, including integrin $\alpha 6$ and $\beta 4$, and a putative NCAM. In these genes, NCAM was confirmed to be reduced in both mRNA and protein levels after curcumin treatment. NCAM had been originally detected in the normal and tumoral pituitary (Jin et al., 1991). This membrane glycoprotein of the immunoglobin superfamily promotes cell-cell adhesion via a homophilic binding mechanism and is related to tumor growth rate and malignancy (Rutishauser and Landmesser, 1996). It is likely that NCAM is involved in tumor cell invasion and the metastatic process by facilitating cell detachment from the primary tumor, migration, and survival in a hostile environment (Franca et al., 2001).

DNA topoisomerases are enzymes that catalyze the passage of individual DNA strand (type I) or double helices (type II) through one another, manifested in the interconversions between topological isomers of DNA (Roth et al., 1998). These enzymes have important roles in the replication, recombination, transcription, chromosome condensation, and the maintenance of genome stability. Hence, they are good targets for antineoplastic drugs (Lin et al., 2000). The inhibition of topoisomerases could induce cell apoptosis and inhibit cell cycle progression and tumorigenesis (Bronner et al., 2002). The two major DNA isomerases in human cells (TOPO-I and II) have been firmly established to be effective molecular targets for many antitumor drugs (camptothecins and actinomycin D for TOPO-I; doxorubicin, daunorubicin, mitoxantrone, and etoposide for TOPO-II) (Lin et al., 2000). Previously, curcumin has been identified to inhibit the activity of TOPO-II

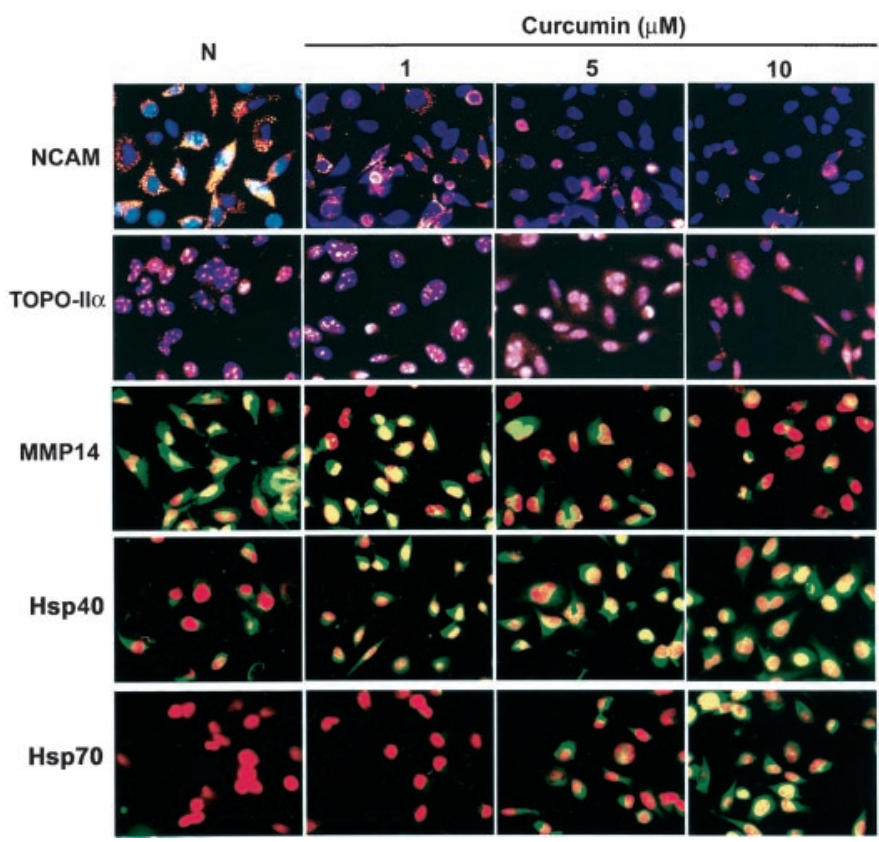

Fig. 5. Immunohistochemical analysis. The CL1-5 cells were treated with $(1,5$, and $10 \mu \mathrm{M})$ or without $(\mathrm{N})$ curcumin, and then fixed with acetone for $5 \mathrm{~min}$ before staining as described under Materials and Methods. Specific antibodies for NCAM, MMP14 (MT1-MMP), TOPO-II $\alpha$, Hsp27, Hsp40, and Hsp70 were used in the immunostaining. After Rhodamine (orange fluorescence for NCAM or TOPO-II $\alpha$ ) or fluorescein isothiocyanate- (green fluorescence for MMP14, Hsp27, Hsp40, and Hsp70) conjugated secondary antibodies incubation, the cells were examined under fluorescence microscopy (Leica). 4,6-Diamidino-2-phenylindole (DAPI) (blue fluorescence) or propidium iodide (red fluorescence) was used as the counterstain of the cell nuclei. Similar results of the blotting images were obtained in four additional experiments $(n=4)$. and exhibit the topoisomerase-poisoning effect (Roth et al., 1998). In the present study, both mRNA and protein expression levels of TOPO-I and II were confirmed to be reduced after curcumin treatment. The transcriptional regulation of

\section{Curcumin $(\mu \mathrm{M})$}

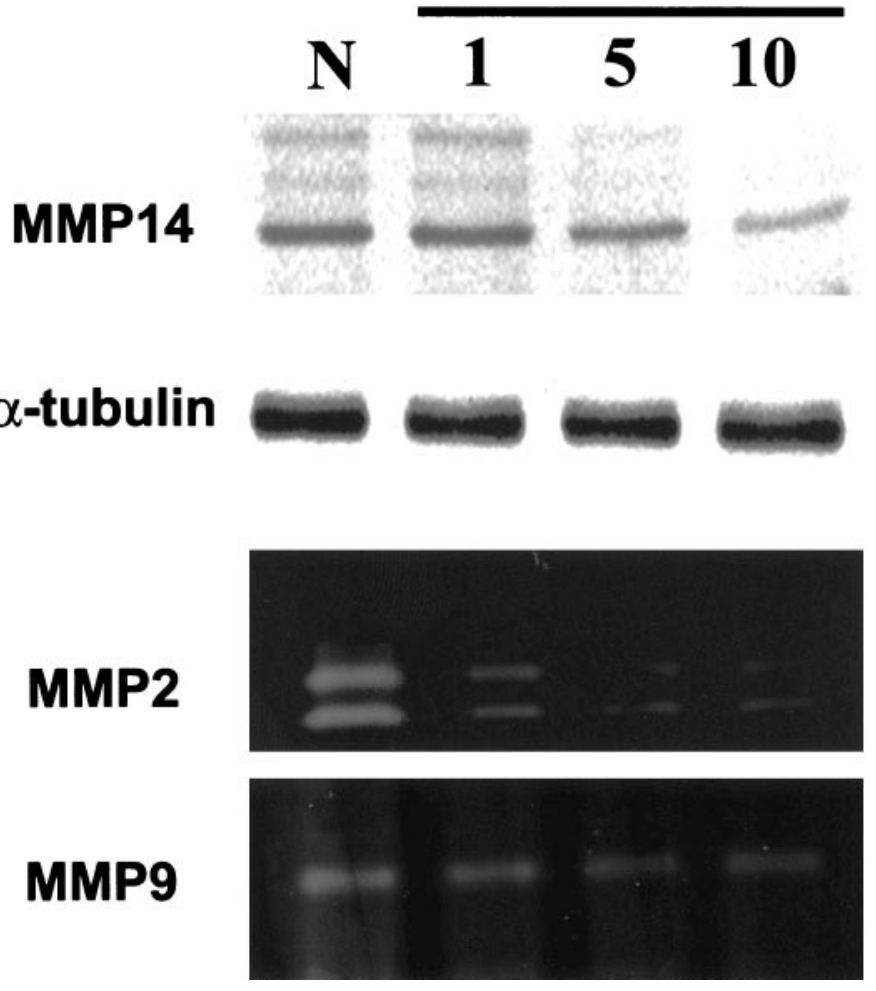

Fig. 6. Western blotting of MMP14 and zymographic analysis of MMP2 and nine activities. The CL1-5 cells were treated with $(1,5$, and $10 \mu \mathrm{M})$ or without $(\mathrm{N})$ curcumin for $24 \mathrm{~h}$ and the conditioned medium and cells were harvested separately for zymographic analysis. The effects of curcumin $(0,1,5$, and $10 \mu \mathrm{M})$ on MMP14 protein expression and also on MMP2 and MMP9 gelatinolytic activity were studied. Gelatin zymography developed in the presence of increasing concentrations of curcumin shows a progressively faint digestion band. Similar results of the zymographic images were obtained in three additional experiments.

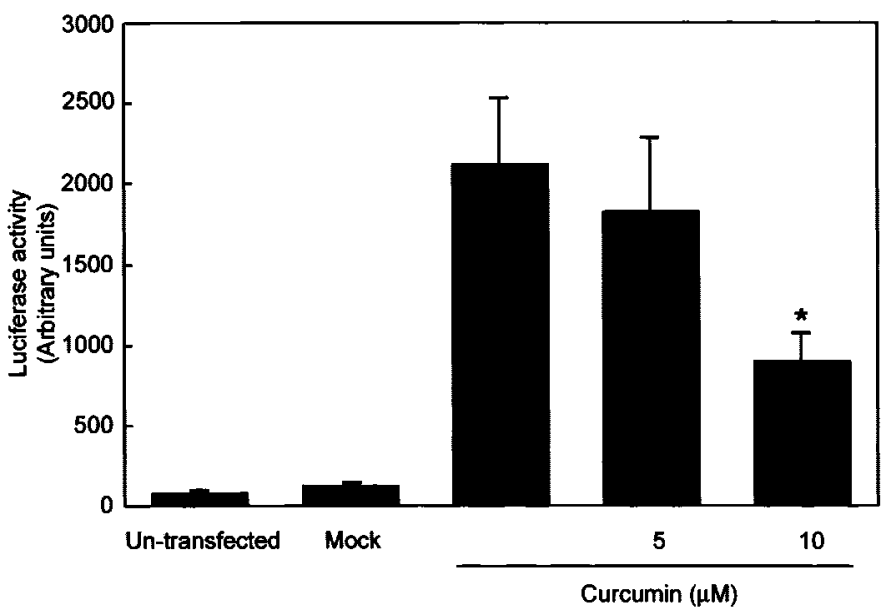

Fig. 7. Reporter gene assay of NF- $\kappa$ B transcriptional activity. CL1- 5 cells were transfected with NF- $\mathrm{B}$ binding domain luciferase construct and then treated with curcumin $(5$ and $10 \mu \mathrm{M})$. Luciferase activity assay was performed, and the results showed that it was significantly decreased in $10 \mu \mathrm{M}$ curcumin-treated cells. *, $P<0.05$, compared with untreated control. 
TOPO I and II genes and species-specific differences are still unclear (Bronner et al., 2002).

Curcumin is a well known regulator of some certain transcriptional factors, which has been reported to inhibit AP-1 and $\mathrm{NF}-\kappa \mathrm{B}$ in transcriptional regulation in many cell systems (Philip and Kundu, 2003). The NF- $\mathrm{B}$ transcriptional activity was also significantly inhibited by curcumin in CL1-5 cells. The promoters of the genes MMP-2, MT1-MMP, NCAM, and Top-II $\alpha$, showing significant down-regulation after curcumin treatment in CL1-5 cells, have AP-1 and/or NF- $\kappa$ B regulatory site (CTGACCTCC and/or TGGAGCTTCC) (Aggarwal et al., 2003; Bergman et al., 2003). Some of the other genes (Top-I and MT1-MMP) could be regulated by SP-1, NF-Y, YB-1, or other transcriptional factors. Previous studies also showed that SP-1 and YB-1 could be regulated by AP-1 and NF- $\kappa$ B. Furthermore, we also found that the expression of v-ets, the AP-1 cooperator, could be inhibited by curcumin. Our results supported the idea that curcumin could down-regulate these proteins (MT1-MMP, NCAM, Top-I, and Top-II $\alpha$ ) partially through inhibiting AP-1 and $\mathrm{NF}-\kappa \mathrm{B}$. Whether other transcriptional factors or signal transductional pathways might involve in curcumin-inhibited cell invasion, further studies are needed to clarify this notion.

During carcinogenesis, HSPs have been reported to show alteration of their expression levels, either increasing or decreasing. Several findings have demonstrated that HSPs are associated with cell proliferation, differentiation, viability, apoptosis, motility, and antitumor immunity (Rousseau et al., 1997), but their clinical significance is still controversial. A statistically significant positive correlation between the amount of HSP (hsp27 and -70) expression and patient survival has been also reported in esophageal carcinoma patients (Kawanishi et al., 1999). Patients with HSP-positive tumors can be expected to display a better prognosis than those with HSP-negative tumors.

We had previously identified that the expression of Hsp27 and Hsp40-like protein correlated with the invasive ability of lung cancer cell lines (Chen et al., 2001). In the present study, Hsp27, Hsp40-like protein, and Hsp70 were up-regulated by curcumin. Previous studies have also shown that curcumin could induce the heat shock response in vitro as measured by expression of Hsp70 in Hela cells (Dunsmore et al., 2001). The roles of these HSPs in curcumin-regulated tumor cell proliferation and invasion are still unclear and require additional study. These HSPs may have potential for anticancer therapeutic uses and are worthy of further investigation.

Several genes whose expression was not altered by curcumin in this study have been reported elsewhere to be involved in curcumin-regulated cell proliferation, apoptosis, or cancer invasion, including c-jun, c-fos, c-myc, bcl-2, bcl-xl, p53, cyclin B, cyclin D1, COX-2, and MMP9 (Shishodia et al., 2003). It might be suggested that curcumin-regulated pathways were differed in different cell types. Previous study has also shown that curcumin-induced cell death and antiproliferation was caused neither by apoptosis nor by any significant change in the expression of apoptosis-related genes, including bcl-2, p53, cyclin $B$, and transglutaminase in human breast tumor cell lines (Mukhopadhyay et al., 2001). In the present study, TOPO-I, II $\alpha, \mathrm{NF}-\kappa \mathrm{B}$, and heat shock proteins (Hsp27, -40, and -70) seem play the major roles in the anti-invasive and antiproliferative effects of curcumin in CL1-5 cells.

The results of this comprehensive survey demonstrated that curcumin exhibits antimetastatic activity in lung carcinoma cells. The anticancer potential of curcumin stems from its ability to suppress cancer cell proliferation and invasion by down-regulating the expression of MT1-MMP, NCAM, TOPO-I and II, and AXL-receptor tyrosin kinase and inhibiting the activity of MMP2 and the transcriptional activity of NF- $\kappa$ B. Conversely, the HSPs (Hsp27, Hsp40-like protein, and Hsp70) were up-regulated by curcmin. Nonetheless, their role in curcumin-regulated cell proliferation and invasion still requires additional evidence. The use of cDNA microarrays in this study has provided a global view of the cellular response of cancer cells to curcumin at genomic levels. Such global analysis of the anti-invasion response to the development of new novel drugs will require additional insight into the mechanisms of drug action for the treatment of cancer and allow for a more rational design of effective treatment strategies.

\section{References}

Aggarwal BB, Kumar A, and Bharti AC (2003) Anticancer potential of curcumin preclinical and clinical studies. Anticancer Res 23:363-398.

Bergman MR, Cheng S, Honbo N, Piacentini L, Karliner JS and Lovett DH (2003) A functional activating protein 1 (AP-1) site regulates matrix metalloproteinase 2 (MMP-2) transcription by cardiac cells through interactions with JunB-Fra1 and JunB-FosB heterodimers. Biochem $J$ 369:485-496.

Bronner C, Hopfner R, and Mousli M (2002) Transcriptional regulation of the human topoisomerase II alpha gene. Anticancer Res 22:605-612.

Chen HW and Huang HC (1998) The effects of curcumin on cell cycle progression and apoptosis in vascular smooth muscle cells. Br J Pharmacol 124:1029-1040.

Chen HW, Chen JJW, Tzeng CR, Li HN, Chang SJ, Cheng YF, Chang CW, Wang RS,

Yang PC, and Lee YT (2002a) Global analysis of differentially expressed genes in early gestational decidua and chorionic villi using a 9600 human cDNA microarray. Mol Hum Reprod 8:475-484.

Chen HW, Chien CT, Yu SL, Lee YT, and Chen WJ (2002b) Cyclosporine A regulate oxidative stress-induced apoptosis in cardiomyocytes: mechanisms via ROS generation, iNOS and Hsp70. Br J Pharmacol 137:771-781.

Chen JJW, Peck K, Hong TM, Yang SC, Sher YP, Shih JY, Wu R, Cheng JL, Roffler $\mathrm{SR}, \mathrm{Wu} \mathrm{CW}$, et al. (2001) Global analysis of gene expression in invasion by a lung caner model. Cancer Res 61:5223-5230.

Chen JJW, Yao PL, Yuan A, Hong TM, Shun CT, Kuo ML, and Yang PC (2003) Up-regulation of tumor interleukin-8 expression by infiltrating macrophages: its correlation with tumor angiogenesis and patient survial in non-small cell lung cancer. Clin Cancer Res 9:729-737.

Chu YW, Yang PC, Yang SC, Shyu YC, Hendrix MJC, Wu R, and Wu CW (1997) Selection of invasive and metastatic subpopulations from a human lung adenocarcinoma cell line. Am J Respir Cell Mol Biol 17:353-360.

Dell'Aica I, Dona M, Sartor L, Pezzato E, and Garbisa S (2002) (-)Epigallocatechin3-gallate directly inhibits MT1-MMP activity, leading to accumulation of nonactivated MMP-2 at the cell surface. Lab Investig 82:1685-1693.

Dunsmore KE, Chen PG, and Wong HR (2001) Curcumin, a medicinal herbal com pound capable of inducing the heat shock response. Crit Care Med 29:2199-2204 Fillmore HL, VanMeter TE, and Broaddus WC (2001) Membrane-type matrix metalloproteinases (MT-MMPs): expression and function during glioma invasion. J Neurooncol 53:187-202

Franca CM, Jaeger RG, Freitas VM, Araujo NS, and Jaeger MM (2001) Effect of $\mathrm{N}-\mathrm{CAM}$ on in vitro invasion of human adenoid cystic carcinoma cells. Oral Oncology 37:638-642.

Govindarajan VS (1980) Turmeric: chemistry, technology and quality. Crit Rev Food Sci Nutr 12:199-301.

Gururaj AE, Belakavadi M, Venkatesh DA, Marme D, and Salimath BP (2002) Molecular mechanisms of anti-angiogenic effect of curcumin. Biochem Biophys Res Commun 297:934-942.

Hong RL, Spohn WH, and Hung MC (1999) Curcumin inhibits tyrosine kinase activity of p185neu and also depletes p185neu. Clin Cancer Res 5:1884-1891.

Hong TM, Yang PC, Peck K, Chen JJW, Yang SC, Chen YC, and Wu CW (2000) Profiling the down stream genes of tumor suppressor PTEN in lung cancer cells by cDNA microarray. Am J Respir Cell Mol Biol 23:355-363.

Huang MT, Smart RC, Wong CQ, and Conney AH (1988) Inhibitory effect of curcumin, chlorogenic acid and ferulic acid on tumor promotion in mouse skin by 12-O-tetradecanoylphorbol-13-acetate. Cancer Res 48:5941-5946.

Iyer VR, Eisen MB, Ross DT, Schuler G Moore T, Lee JC, Trent JM, Staudt LM, Hudson J Jr, and Boguski MS (1999) The transcriptional program in the response of human fibroblasts to serum. Science (Wash DC) 283:83-87.

Jain VK and Magrath IT (1991) A chemiluminescent assay for quantitation of beta-galactosidase in the femtogram range: application to quantitation of betagalactosidase in lacZ-transfected cells. Anal Biochem 199:119-124.

Jin L, Hemperly JJ, and Lloyd RV (1991) Expression of neural cell adhesion molecule in normal and neoplastic human neuroendocrine tissue. Am J Pathol 138:961-969. 
Kawanishi K, Shiozaki H, Doki Y, Sakita I, Inoue M, Yano M, Tsujinaka T, Shamma A, and Monden M (1999) Prognostic significance of heat shock proteins 27 and 70 in patients with squamous cell carcinoma of the esophagus. Cancer 85:1649-1657.

Koopman G, Reutelingsperger CP, Kuijten GA, Keehnen RM, Pals ST, and van Oers MH (1994) Annexin V for flow cytometric detection of phosphatidylserine expression on B cells undergoing apoptosis. Blood 84:1415-1420.

Lin JK, Pan MH, and Lin-Shiau SY (2000) Recent studies on the biofunctions and biotransformations of curcumin. Biofactors 13:153-158.

Menon LG, Kuttan R, and Kuttan G (1999) Anti-metastatic activity of curcumin and catechin. Cancer Lett 141:159-165.

Menon LG, Kuttan R, and Kuttan G (1995) Inhibition of lung metastasis in mice induced by B16F10 melanoma cells by polyphenolic compounds. Cancer Let $\mathbf{9 5}$ $221-225$.

Mukhopadhyay A, Bueso-Ramos C, Chatterjee D, Pantazis P, and Aggarwal BB (2001) Curcumin downregulates cell survival mechanisms in human prostate cancer cell lines. Oncogene 2001 20:7597-7609.

Nagase H and Woessner JF Jr (1999) Matrix metalloproteinases. J Biol Chem 274:21491-21494.

Onodera S, Nishihira J, Iwabuchi K, Koyama Y, Yoshida K, Tanaka S, and Minam A (2002) Macrophage migration inhibitory factor up-regulates matrix metalloproteinase- 9 and -13 in rat osteoblasts. Relevance to intracellular signaling pathways. $J$ Biol Chem 277:7865-7874.

Philip S and Kundu GC (2003) Osteopontin induces nuclear factor kappa B-mediated promatrix metalloproteinase- 2 activation through $\mathrm{I} \kappa \mathrm{B} \alpha / \mathrm{IKK}$ signaling pathways and curcumin (diferulolylmethane) down-regulates these pathways. J Biol Chem 278:14487-14497.

Roth GN, Chandra A, and Nair MG (1998) Novel bioactivities of Curcuma longa constituents. J Nat Prod 61:542-545.

Rousseau S, Houle F, Landry J, and Huot J (1997) p38 map kinase activation by vascular endothelial growth factor mediates actin reorganization and cell migration in human endothelial cells. Oncogene 15:2169-2177.
Rutishauser U and Landmesser L (1996) Polysialic acid in the vertebrate nervous system: a promoter of plasticity in cell-cell interactions. Trend Neurosci 19:422 427.

Shishodia S, Potdar P, Gairola CG, and Aggarwal BB (2003) Curcumin (diferuloyl methane) down-regulates cigarette smoke-induced NF-kappaB activation through inhibition of IkappaBalpha kinase in human lung epithelial cells: correlation with suppression of COX-2, MMP-9 and cyclin D1. Carcinogenesis 24:1269-1279.

Skubitz AP (2002) Adhesion molecules. Cancer Treat Res 107:305-329.

Tamayo P, Slonim D, Mesirov J, Zhu Q, Kitareewan S, Dmitrovsky E, Lander ES, and Golub TR (1999) Interpreting patterns of gene expression with self-organizing maps: methods and application to hematopoietic differentiation. Proc Natl Acad Sci USA 96:2907-2912.

Thaloor D, Singh AK, Sidhu GS, Prasad PV, Kleinman HK, and Maheshwari RK (1998) Inhibition of angiogenic differentiation of human umbilical vein endothelial cells by curcumin. Cell Growth Differ 9:305-312.

Théret N, Musso O, L'Helgoualc'h A, Campion JP and Clément B (1998) Differential expression and origin of membrane-type 1 and 2 matrix metalloproteinases (MTMMPs) in association with MMP2 activation in injured human livers. Am J Pathol 153:945-954.

Vermes I, Haanen C, Steffens-Nakken H, and Reutelingsperger C (1995) A novel assay for apoptosis. Flow cytometric detection of phosphatidylserine expression on early apoptotic cells using fluorescein labelled Annexin V. J Immunol Methods 184:39-51.

Vihinen P and Kahari VM (2002) Matrix metalloproteinases in cancer: prognostic markers and therapeutic targets. Int $J$ Cancer 99:157-166.

Address correspondence to: Dr. Pan-Chyr Yang, Department of Internal Medicine, National Taiwan University Hospital, 7 Chung Shan South Road, Taipei, Taiwan 100, ROC. E-mail: pcyang@ha.mc.ntu.edu.tw 